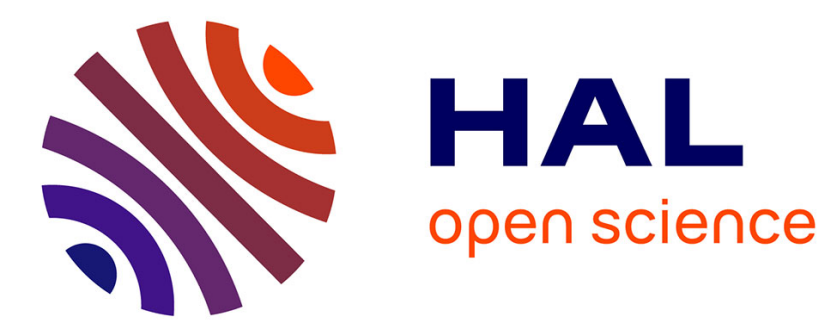

\title{
P-glycoprotein influences urinary excretion of aldosterone in healthy individuals
}

P. Marques, P.-Y. Courand, I. Gouin-Thibault, V. Zhygalina, D. Bergerot, J.-E. Salem, C. Funck-Brentano, M.-A. Loriot, M. Azizi, A. Blanchard

\section{- To cite this version:}

P. Marques, P.-Y. Courand, I. Gouin-Thibault, V. Zhygalina, D. Bergerot, et al.. P-glycoprotein influences urinary excretion of aldosterone in healthy individuals. Journal of Hypertension, Lippincott, Williams \& Wilkins, 2019, 37 (11), pp.2225-2231. 10.1097/HJH.0000000000002150 . hal-02365586

\section{HAL Id: hal-02365586 \\ https://hal-univ-rennes1.archives-ouvertes.fr/hal-02365586}

Submitted on 25 Nov 2019

HAL is a multi-disciplinary open access archive for the deposit and dissemination of scientific research documents, whether they are published or not. The documents may come from teaching and research institutions in France or abroad, or from public or private research centers.
L'archive ouverte pluridisciplinaire HAL, est destinée au dépôt et à la diffusion de documents scientifiques de niveau recherche, publiés ou non, émanant des établissements d'enseignement et de recherche français ou étrangers, des laboratoires publics ou privés. 


\section{P-GLYCOPROTEIN INFLUENCES URINARY EXCRETION OF ALDOSTERONE IN HEALTHY SUBJECTS}

MARQUES Pedro, ${ }^{1}$ COURAND Pierre-Yves, ${ }^{2,3}$ GOUIN-THIBAULT Isabelle, ${ }^{4,5,6}$ ZHYGALINA Valentina, ${ }^{2,7,8}$ BERGEROT Damien ${ }^{2,7,8}$, SALEM Joe-Elie, ${ }^{9,10,11,12}$ FUNCK-BRENTANO Christian, 9,10,11, 12 LORIOT Marie-Anne, ${ }^{4,13,14}$ AZIZI Michel, ${ }^{2,7,8,15}$ BLANCHARD Anne ${ }^{2,7,8}$

${ }^{1}$ Department of Internal Medicine, C. Hospitalar Universitario S. João, Porto, Portugal; ${ }^{2}$ Assistance Publique Hôpitaux de Paris, Georges Pompidou European Hospital, Centre d'Investigation Clinique, Paris, France; ${ }^{3}$ Hospices civils de Lyon, Croix-Rousse and Lyon-Sud Hospital, Department of Cardiology, Lyon, France; ${ }^{4}$ Hematology Laboratory, University Hospital, Rennes, France; ${ }^{5}$ CIC_INSERM1414, Rennes 1 University, France; ${ }^{6}$ INSERM UMR_S1140, Pharmacy faculty, Paris, France; ${ }^{7}$ Paris Descartes University, Sorbonne Paris Cité, Paris, France; ${ }^{8}$ INSERM, CIC-1418, Paris, France; ${ }^{9}$ AP-HP, PitiéSalpêtrière Hospital, Department of Pharmacology and CIC-1421, F-75013 Paris, France; ${ }^{10}$ INSERM, CIC1421 and UMR ICAN 1166, F-75013 Paris, France; ${ }^{11}$ Sorbonne Universités, UPMC Univ Paris 06, Faculty of Medicine, Department of Pharmacology, F-75013 Paris, France; ${ }^{12}$ Institute of Cardiometabolism and Nutrition (ICAN), F-75013 Paris, France; ${ }^{13}$ Assistance Publique-Hôpitaux de Paris, Georges Pompidou European Hospital, Department of Biochemistry, Paris, France; ${ }^{14}$ INSERM UMR_S1147, Saints-Pères University Center, Paris, France; ${ }^{15}$ Assistance Publique Hôpitaux de Paris, Georges Pompidou European Hospital, Arterial Hypertension unit, Paris, France.

SOURCES OF FUNDING: This work was funded by the "Contrat de Recherche Clinique from the Assistance Publique des Hôpitaux de Paris" (grant \#: CRC10128).

DISCLOSURES The authors have no disclosures in relation to this study.

CONFLICT OF INTEREST The authors have no conflict of interest in relation to this study.

\section{CORRESPONDING AUTHOR:}

\section{Anne BLANCHARD}

Centre d'investigation Clinique, Hôpital Européen Georges Pompidou, 20-40 rue Leblanc 75015 PARIS

anne.blanchard@aphp.fr

Phone $\quad 0033156092913$

Fax 0033156092929

Word count (including references): 4253

Abstract word count: 248

Number of tables: 2

Number of figures: 2

Number of supplementary digital content files: 0 


\section{ABSTRACT}

Objectives: P-glycoprotein (P-gp), the product of the $A B C B 1$ gene, is involved in the transport of aldosterone and cortisol in adrenal cells in vitro but its physiological role in humans remains controversial. Our objective was to test the influence of $\mathrm{P}$-gp polymorphisms on aldosterone.

Methods: We evaluated plasma aldosterone concentration (PAC), urinary aldosterone (UA), and blood pressure (BP) in a cohort of Caucasian normotensive men (i) at baseline on diets unrestricted for sodium and potassium and (ii) after a 5-day treatment with $500 \mathrm{mg}$ b.i.d. clarithromycin, a P-gp inhibitor. Included were 20 homozygous wild-type (P-gp0), 20 heterozygous (P-gp1), and 20 subjects with combined 2677G >T/A-3435C >T loss-of-function polymorphism of the $A B C B 1$ gene (P-gp2).

Results: At baseline, PAC, UA, urinary free cortisol to urine creatinine ratios, and BP did not differ in the three genotypes. After clarithromycin administration, the UA to creatinine ratio (UAC) increased by an average of $30 \%$ in the entire cohort $(p<0.001, n=60)$. Increases were pronounced in $\mathrm{P}-\mathrm{gp} 1(+40 \%$; $\mathrm{p}=0.014)$ and P-gp2 subjects (+50\%; $\mathrm{p}=0.020)$ but lesser and were not significant in P-gp0 subjects $(+10 \% ; p=0.259)$. PAC also increased from baseline after clarithromycin treatment in all subjects $(+19 \%, p=0.050)$; however, the increase in PAC was not significant when the three genotypes were analyzed separately.

Conclusion: In our experimental conditions, the interaction between P-gp inhibition and the $A B C B 1$ genotype, suggests (i) that aldosterone is indeed a physiological endogenous substrate of P-gp in humans and (ii) that P-gp interferes with the net equilibrium between aldosterone secretion and elimination processes in humans.

Clinical Trial Registration - URL: http://www.clinicaltrials.gov. Unique identifier: NCT01627665

Keywords: P-glycoprotein, renin-angiotensin system, aldosterone, renin, polymorphism, $A B C B 1$ gene, clarithromycin 


\section{INTRODUCTION}

P-glycoprotein (P-gp), also known as multi-drug resistance protein 1 (MDR1), is a transmembrane efflux protein encoded by the $A B C B 1$ [ATP-binding cassette, sub-family $B$ (MDR/TAP), member 1] gene in humans ${ }^{1}$. It was first identified from multi-drug resistant cancer cells ${ }^{2}$ and has since been shown to be present in normal human tissues such as proximal tubule of the kidney, bronchial cells, small intestine sweat glands, and capillary endothelium of brain, skin, testes, and adrenals ${ }^{3}$. Its main functions are thought to be limiting absorption of xenobiotics from the gut, thus favoring their biliary and renal elimination, and protection of sensitive tissues (brain, testes) and fetal tissue from these compounds ${ }^{4}$. P-gp binds and transports a large number of drugs, playing an important role in their absorption and disposition ${ }^{5}$. Drugs that bind to P-gp include potent antagonists of its function ${ }^{6,7}$. Various polymorphisms of the $A B C B 1$ gene that alter its expression and/or function have been described ${ }^{5,8,9}$. Among them, two single nucleotide polymorphisms (SNP) in linkage disequilibrium, 2677G >T/A (rs2032582, p.A893S/T) in exon 21 and 3435C $>$ T (rs1045642, p.11145I) in exon 26 are common, particularly in Caucasians, and are associated with variations in P-gp expression and activity in humans and in cell lines ${ }^{1}$. The SNP $3435 C>T$ is associated with lower P-gp expression in B cell chronic lymphocytic leukemia and human duodenum in subjects with the TT genotype compared to the $\mathrm{CT}$ or CC genotypes. This mutation is associated with decreased transport activity of P-gp in vitro and in vivo ${ }^{10,11}$. Both $2677 \mathrm{G}>\mathrm{T} / \mathrm{A}$ and $3435 \mathrm{C}>\mathrm{T}$ SNPs were shown to alter pharmacokinetics of drug metabolism ${ }^{9}$.

P-gp also transports several steroid hormones including corticosterone, cortisol, aldosterone, and progesterone and plays a protective role against accumulation of these hormones in the brain, heart, and testes ${ }^{12-14}$. The high expression of P-gp in adrenal glands and its ability to transport steroids in vitro led to the hypothesis that $\mathrm{P}$-gp contributes to aldosterone and cortisol secretion from the adrenal cortex in vivo ${ }^{15}$. The physiological relevance of these findings is unclear, and data supporting this hypothesis are scarce. A decrease in plasma cortisol and an increase in plasma aldosterone concentrations were reported in the postmenstrual phase of women with the homozygous $3435 \mathrm{C}>\mathrm{T}$ genotype ${ }^{16}$. Moreover, cyclosporine A, a potent P-gp inhibitor, was shown to inhibit the angiotensin IImediated stimulation of aldosterone secretion by glomerular adrenal cells in vitro ${ }^{17}$, suggesting that $\mathrm{P}$ gp may contribute to the relative adrenal resistance (high renin/low aldosterone concentrations) observed in patients treated with this drug ${ }^{18}$. Finally, $A B C B 1$ gene polymorphisms were shown to influence blood pressure (BP) and response to treatment, and this effect is modified by salt intake ${ }^{19,20}$. 
We investigated the physiological role of P-gp in humans by (i) studying the impact of the combined $2677 G>T / A-3435 C>T$ loss-of-function polymorphism of the $A B C B 1$ gene on the concentration of aldosterone and (ii) analyzing the impact of $A B C B 1$ status on plasma renin concentration, potassium and sodium metabolism, and BP in normotensive healthy men. In addition, we studied for the first time the effects of pharmacologic inhibition of P-gp and CYP3A4 by clarithromycin in these subjects.

\section{METHODS}

\section{Study participants}

This substudy testing the influence of P-gp on aldosterone and renin concentrations was nested within the DRIVING study, which was designed to test the influence of the $A B C B 1$ genotype and clarithromycin on the pharmacokinetics of a single dose of new oral anticoagulant drugs dabigatran etexilate and rivaroxaban ${ }^{21}$. The study was approved by the Comité de Protection des Personnes lle de France $X$ and the Agence Nationale de Sécurité des Médicaments and registered on www.clinicaltrial.gov registry (NCT 01627665). All participants gave their written informed consent to participate.

Healthy Caucasian male volunteers aged 18 to 45 years were recruited at two Clinical Investigation Centers in Paris, France (Georges Pompidou European Hospital and Paris-Est Pitié-Salpêtrière University Hospital). They were eligible if their supine office blood pressure (BP) was less than 140 and $90 \mathrm{mmHg}$ and their body mass index (BMI) was $18-28 \mathrm{~kg} / \mathrm{m}^{2}$, and their clinical, routine biochemical and ECG evaluations were normal. Exclusion criteria were a history of allergy, ongoing chronic disease, acute disease within the past 8 days, use of medication within the past 8 days, or history of substance abuse or tobacco or alcohol consumption. Sodium and potassium in the diet were unrestricted throughout the study.

After genetic screening of 224 eligible subjects, we included 60 subjects according to their $A B C B 1$ genotype: 20 subjects were wild-type homozygous ( $\mathrm{P}$-gp0 group), 20 were heterozygous mutated ( $\mathrm{P}$ gp1 group), and 20 were homozygous mutated (P-gp2 group) for the $A B C B 1$ haplotype 2677G>T/A$3435 C>T$, as previously reported ${ }^{21}$.

\section{Study design}

The design of the DRIVING study was previously reported ${ }^{21}$. For this substudy, all subjects were studied under basal conditions and after 5 days of oral administration of clarithromycin $500 \mathrm{mg}$ b.i.d. Clarithromycin is a potent inhibitor of both P-gp and CYP3A4 ${ }^{21}$. On both study days, blood was 
sampled at 09.00 a.m. after a 1-hour rest in the semi-recumbent position after an overnight fast. Subjects were instructed to collect a 24-hour urine sample the day before each visit. Supine office BP was measured with a validated electronic device (Welchalin VSM300, New York, USA). Subjects followed an unrestricted salt isocaloric diet. The dose and duration of clarythromycin administration selected for the study was previously shown to inhibit P-gp and CYP3A4 activities and to lead to a twofold increase in both rivaroxaban and dabigatran exposure ${ }^{21}$. This was independent of the $A B C B 1$ genotype, which did not affect the pharmacokinetics of the two drugs.

\section{Laboratory methods}

Plasma and urine samples were stored at $20^{\circ} \mathrm{C}$ until analysis. Plasma renin concentration (PRC) was measured using an immunoradiometric assay (Renin III, CisBio, Codolet, France). Plasma aldosterone concentration (PAC) and 24-h urinary excretion of free aldosterone at $\mathrm{pH} 1$ (UAE) were measured using a radioimmunoassay (Coat-a-count, Siemens Medical Solutions Diagnostics, Erlangen, Germany). 24-h urinary free cortisol Excretion (UFCE) was measured by radioimmunoassay (Cortisol RIA kit, Beckman Coulter). The ratio of UAE and UFCE to urinary creatinine excretion was used to standardize the 24hour urine collection. Glomerular filtration rate (GFR) was estimated with the simplified modification of diet in renal disease (MDRD) formula. To account for differences in diet between genotypes and visits, if any, 24-hour urinary sodium and potassium excretion were measured. All biochemical and hormonal assessments were performed blind to the genotype.

\section{Statistical analysis}

We used analysis of variance for normally distributed variables or the Kruskal-Wallis non-parametric tests for non-normally distributed variables to compare the characteristics between genotypes. We used the Student's paired t-test to compare hemodynamic and hormonal parameters before and after clarithromycin administration. We used linear regression with Pearson's coefficient of correlation to assess the relationships between variables. Non-normally distributed variables were log-transformed where appropriate because of skewed distribution.

Data are expressed as means \pm one standard deviation (SD) or as medians [interquartile range, IQR]. We used SPSS 20.0.0 program (SPSS, Chicago, IL, USA) for statistical analysis. A $P$ value of $<0.05$ was considered as statistically significant. 


\section{RESULTS}

The median age of the healthy male subjects was 28.1 [23.8-38.9] years and their BP was $114 \pm 8 / 68 \pm$ $6 \mathrm{mmHg}$ at baseline (Table 1). There was no significant difference in age, BMI, heart rate, systolic and diastolic BP, GFR, or plasma electrolytes between genotypes (Table 1). Dietary sodium and potassium intakes were similar as shown by the similar urinary sodium and potassium excretions between genotypes (Table 1).

\section{INFLUENCE OF 2677-3435 HAPLOTYPE ON RENIN, ALDOSTERONE AND CORTISOL CONCENTRATIONS}

At baseline, PAC, UAE, and PRC did not significantly differ between the three genotypes (Table 1). As expected, there was a significant positive correlation between log-transformed PAC and PRC ( $r=0.509$, $p<0.001)$ in the entire cohort $(n=60)$, which was also observed within each of the three genotypes with no difference in the slope of the intercept of the relationship between genotypes. When P-gp1 and Pgp2 subjects $(n=40)$ were grouped and compared to P-gp0 $(n=20)$ subgroups, there were not statistically significant differences in PAC $(+0 \%, p=0.983), \operatorname{PRC}(-18 \%, p=0.159)$, or UAE $(+11 \%, p=0.606$, P-gp1-2 vs. P-gp0, respectively). There was no difference of UFCE to urinary creatinine excretion between genotypes.

\section{EFFECT OF CLARITHROMYCIN ON ALDOSTERONE, RENIN AND CORTISOL}

After 5 days of oral clarithromycin administration, there were no significant changes from baseline in BP or HR when the entire cohort $(n=60)$ was considered $(114 \pm 8 / 68 \pm 6 \mathrm{mmHg}$ vs. $114 \pm 8 / 69 \pm 6$ $\mathrm{mmHg}, p=0.490$ for systolic BP and $p=0.239$ for diastolic BP; $62 \pm 9$ vs. $62 \pm 10$ beats per minute, $p=0.947)$. The urinary sodium and potassium to creatinine ratios remained stable indicating that dietary intake did not change. In the whole cohort urinary sodium excretion was $136 \pm 55 \mathrm{mmol}$ per day ( $p=0.190$ vs. baseline) and urinary sodium to creatinine ratio was $10.4 \pm 4.4$ ( $p=0.956$ vs. baseline). Potassium urinary excretion was $6.3 \pm 2.1 \mathrm{mmol}$ per day ( $p=0.836$ vs. baseline) and urinary potassium to creatinine ratio was $9.4 \pm 1.7$ ( $p=0.413$ vs. baseline). After 5 days of clarithromycin, there were no significant difference between subgroups of P-gp for urinary sodium excretion $(p=0.329)$, urinary sodium to creatinine ratio $(p=0.570)$, potassium urinary excretion $(p=0.768)$ and urinary potassium to creatinine ratio $(p=0.608)$. In the entire cohort $(n=60)$, PAC increased slightly from baseline $(+19 \%$, $\mathrm{p}=0.050$ ); however, PAC change from baseline were not significant in any of the three genotypes. There were no significant changes from baseline in PRC in the overall population or in the three genotypes. After treatment, PRC was lower in the P-gp0 groups than in the two other subgroups (P- 
gp0: 15 [11-21] vs. P-gp1 and P-gp2: 20 [15-31] p=0.043). The relationship between log-transformed PAC and PRC after 5 days of of oral clarithromycin administration was similar to that at baseline.

In contrast, the UAC increased after 5 days of clarithromycin in the whole population $(+30 \%, p<0.001)$. Differences were significant in P-gp2 subjects $(48 \%[-3 \% ;+134 \%] \mathrm{p}=0.020)$ and $\mathrm{P}$-gp1 subjects $(+39 \%$ [+0\%; +99\%]; $\mathrm{p}=0.014)$ but not in P-gp0 subjects $(+11 \%[-16 \% ;+50 \%] ; \mathrm{p}=0.259)$ (Table 2, Figure 1). Conversely, there was no difference of UFCE to urinary creatinine excretion after clarithromycin (Table 2, Figure 1). 


\section{DISCUSSION}

In subjects without sodium or potassium restriction, we found no physiological influence of the combined 2677G $>$ T/A-3435C $>$ T loss-of-function polymorphisms of the $A B C B 1$ gene on aldosterone concentrations (PAC, UAE, and UFC) or on downstream hormonal (PRC), hemodynamic (BP), or electrolyte consequences in healthy normotensive subjects. We then evaluated effects of clarithromycin, which inhibit P-gp as well as CYP3A4 activities, in wild-type homozygous (P-gp0), heterozygous mutated (P-gp1), and homozygous mutated (P-gp2) subjects. Treatment with $500 \mathrm{mg}$ b.i.d. of clarithromycin for 5 days strongly increased urinary aldosterone excretion by approximately $40 \%$ and less markedly increased PAC by approximately $20 \%$ in all subjects, without however influencing PRC, BP, or plasma electrolyte concentrations. Sodium and potassium intakes did not vary from baseline. The effects of clarithromycin were different between the genotypes. A significant postclarithromycin increase in urinary aldosterone excretion was observed in subjects bearing one or two copies of the $2677 \mathrm{G}>\mathrm{T} / \mathrm{A}$ and $3435 \mathrm{C}>\mathrm{T}$ polymorphisms; however, there was no effect of copy number: P-gp1 subjects had a 39\% [0\%; 99\%] increase and P-gp2 subjects a 48\% [-3\%; 134\%] increase in urinary aldosterone excretion. In contrast, the post-clarithromycin increase in urinary aldosterone excretion was not significant $(\sim+10 \%)$ in P-gp0 subjects compared to baseline. The effect of clarithromycin on urinary aldosterone excretion in P-gp1 and P-gp2 subjects was not accompanied by any significant change in PRC. In our experimental conditions, the interaction between P-gp and CYP3A4 inhibition and the $A B C B 1$ genotype suggests (i) that aldosterone, the main steroid hormone secreted by zona glomerulosa of the adrenal cortex, is indeed an endogenous and physiological substrate of P-gp in humans and (ii) that P-gp interferes in a complex way with the net equilibrium of aldosterone secretion and elimination processes in humans.

Plasma aldosterone concentration reflects the balance between its pulsatile synthesis and release by the adrenal zona glomerulosa under the influence of various endogenous factors (angiotensin II, ACTH, potassium, dopamine, etc.) and its continuous clearance from the plasma by renal and biliary mechanisms with a half-life of around 30 minutes ${ }^{22}$. In humans, P-gp may potentially be involved in aldosterone secretion by the adrenal cortex and in its clearance. Secretion of aldosterone from the zona glomerulosa was believed to occur by passive diffusion, a process favored by the relatively small size and high lipid solubility of the hormone, but it can be facilitated by active transmembrane transport ${ }^{23}$. P-gp present at the level of adrenocortical cells may facilitate steroid efflux as shown in vitro ${ }^{15}$, but its relative contribution to aldosterone transport may be minor in vivo. Indeed, conflicting and indirect data on the impact of loss-of-function P-gp polymorphisms on adrenal aldosterone secretion and circulating aldosterone concentrations have been reported. Various previous studies 
have failed to identify any influence of the $2677 \mathrm{G}>\mathrm{T} / \mathrm{A}$ and $3435 \mathrm{C}>\mathrm{T}$ polymorphisms on plasma aldosterone concentrations in basal conditions 14, 20, 24 However other studies found effects of P-g genotype on aldosterone during menstrual cycle (ref Nakamura) or in contrasted angiotensin II conditions. Zolk et al. indeed found that homozygosity for 3435C $>$ T was associated with greater increases in PAC after angiotensin II infusion and a blunted response to an oral sodium load when compared to the wild-type and heterozygous subjects ${ }^{14}$. The authors postulated that the higher stimulation in PAC in the homozygous mutant group was related to a lower P-gp driven UAE in renal

We did not detect any influence of the combined $2677 \mathrm{G}>\mathrm{T} / \mathrm{A}$ and $3435 \mathrm{C}>\mathrm{T}$ loss-of-function polymorphisms on PAC in basal conditions in normotensive subjects. This effect was confirmed by the measurement of UAE, which integrates overall aldosterone secretion over 24 hours and is more sensitive than a single measurement of PAC, since aldosterone secretion is pulsatile and follows a circadian cycle ${ }^{25}$ Concomitant changes in renal and biliary clearances of aldosterone may have masked a defect in aldosterone secretion by the adrenal cortex in subjects bearing the combined $2677 \mathrm{G}>\mathrm{C} / \mathrm{T} / \mathrm{A}$ and $3435 C>$ T SNPs. Indeed, P-gp is also expressed at the apical membrane of renal proximal tubule and liver cells ${ }^{26}$.

The increase in UAC and the concomitant (even milder) increase in PAC after clarithromycin intake suggests that a decrease in extrarenal biliary clearance of aldosterone may have occurred. CYP3A4 and P-gp are both highly expressed in the gastrointestinal tract and liver and act synergistically as a protective barrier to the bioavailability of orally dosed drugs. Thus, both CYP3A4 and P-gp inhibition may have inhibited biliary clearance of aldosterone.

We however previously reported similar impact of clarithromycin on both dabigatran and rivaroxaban exposures while only rivaroxaban is a substrate of CYP3A4) suggesting that clarithromycin effect on pharmacokinetics of these drugs mainly involves P-gP inhibition and do not dramatically affect CYP17A4 activity." There was large inter-individual variability in clarithromycin-induced increase in UAC that was dependent in part on the $A B C B 1$ genotype. Indeed, the effect of clarithromycin on UAC was considerable in both homozygous P-gp2 and heterozygous P-gp1 subjects, whereas it was small and not significant in wild-type homozygous P-gp0 subjects. The potential mechanisms underlying the genotypic-dependent heterogeneity of the aldosterone metabolism response to clarithromycin are summarized in Figure 2.

Our results suggesting that aldosterone is a physiological substrate in humans may help to reconcile the conflicting results reported so far. P-gp exerts a protective role against accumulation of steroids hormones (corticosterone, cortisol, aldosterone, and progesterone) in the adrenals, the renal tubules 
and the biliary tract and also in the brain, heart, and testes ${ }^{12-14}$. Accordingly, after exogenous [3H]aldosterone administration, $\mathrm{P}$-gp-deficient $\left(\mathrm{mdr} 1 \mathrm{a} / 1 \mathrm{~b}^{-/-}\right)$mice have increased [3H]-aldosterone plasma concentrations accompanied by accumulation of radiolabeled hormone in the brain and heart as compared to wild-type mice, showing a key role of P-gp in modulating the effects aldosterone in these organs ${ }^{12,13}$. Whether higher exposure of the brain, cardiovascular system, and kidney to aldosterone exist in subjects with a loss-of-function polymorphism in the $A B C B 1$ gene is unknown, but, if this is the case, it may explain some genotype-phenotype correlations reported in humans. Such phenotypes include a blunted natriuretic response to high sodium diet in healthy subjects bearing the $3435 \mathrm{C}>\mathrm{T}$ SNPs ${ }^{14}$, the linkage of $3435 C>$ T SNPs with day-time systolic blood pressure ${ }^{20}$ and the deleterious effect of 3435 C $>$ T SNPs on renal function in patients with chronic kidney disease ${ }^{27}$.

Our study has some limitations. First, the small sample size of our population may not have had enough power to detect the effect of P-gp polymorphism alone. Only normotensive men were included in our study and sodium dietary status was not controled. Moreover, we did not measure the effect of a salt load or angiotensin II infusion to stress the different genotypes ${ }^{14}$. Finally, our study was not randomized trial with placebo administration and we cannot exclude a "time-effect" during clarithromycin administration. Finally, the short follow-up period may not be sufficient to ascertain differences with clinical relevance.

In conclusion, we report no difference in basal PAC and UAE according to P-gp genotype in normotensive Caucasian healthy males on an ad libitum sodium and potassium diets. By stressing the genotype with clarithromycin, we selectively observed an increase in UAE secretion in subjects heterozygous or homozygous for the 2677G >T/A-3435C > T loss-of-function polymorphisms, showing that aldosterone is a physiological P-gp substrate and that P-gp is involved in aldosterone metabolism. Whether this genotype is associated with aldosterone accumulation into brain, cardiovascular, and renal tissues as observed in $m d r 1 a / 1 b^{-/-}$mice will require further investigation.

\section{Acknowledgments}

This work was supported by the "Contrat de Recherche Clinique from the Assistance Publique des Hôpitaux de Paris" (grant \#: CRC10128). We thank the volunteers who agreed to participate in the study. We thank Dr. Valerie Paquet for the recruitment of healthy volunteers, the nursing staff of the two Clinical Investigation Centers who ran the protocol, especially head nurses Mrs. Jeanne Meunier and Mrs. Anne-Marie Chénier.

\section{Disclosures}

None 


\section{References}

1. Marzolini C, Paus E, Buclin T, Kim RB. Polymorphisms in human mdr1 (p-glycoprotein): Recent advances and clinical relevance. Clinical pharmacology and therapeutics. 2004;75:13-33

2. Cole SP, Bhardwaj G, Gerlach JH, Mackie JE, Grant CE, Almquist KC, Stewart AJ, et al. Overexpression of a transporter gene in a multidrug-resistant human lung cancer cell line. Science. 1992;258:1650-1654

3. Bakos E, Homolya L. Portrait of multifaceted transporter, the multidrug resistance-associated protein 1 (mrp1/abcc1). Pflugers Archiv : European journal of physiology. 2007;453:621-641

4. Fromm MF. Importance of $\mathrm{p}$-glycoprotein at blood-tissue barriers. Trends in pharmacological sciences. 2004;25:423-429

5. Gerloff T. Impact of genetic polymorphisms in transmembrane carrier-systems on drug and xenobiotic distribution. Naunyn-Schmiedeberg's archives of pharmacology. 2004;369:69-77

6. Aller SG, Yu J, Ward A, Weng Y, Chittaboina S, Zhuo R, Harrell PM, et al. Structure of p-glycoprotein reveals a molecular basis for poly-specific drug binding. Science. 2009;323:1718-1722

7. Patel K, Patil A, Mehta M, Gota V, Vavia P. Oral delivery of paclitaxel nanocrystal (pnc) with a dual pgpcyp3a4 inhibitor: Preparation, characterization and antitumor activity. International journal of pharmaceutics. 2014;472:214-223

8. Biedler JL. Genetic aspects of multidrug resistance. Cancer. 1992;70:1799-1809

9. Wolking S, Schaeffeler E, Lerche H, Schwab M, Nies AT. Impact of genetic polymorphisms of abcb1 ( $m d r 1, p$-glycoprotein) on drug disposition and potential clinical implications: Update of the literature. Clinical pharmacokinetics. 2015;54:709-735

10. Hoffmeyer S, Burk O, von Richter O, Arnold HP, Brockmoller J, Johne A, Cascorbi I et al. Functional polymorphisms of the human multidrug-resistance gene: Multiple sequence variations and correlation of one allele with p-glycoprotein expression and activity in vivo. Proceedings of the National Academy of Sciences of the United States of America. 2000;97:3473-3478

11. Jamroziak K, Balcerczak E, Smolewski P, Robey RW, Cebula B, Panczyk M, Kowalczyk M et al. Mdr1 (abcb1) gene polymorphism c3435t is associated with p-glycoprotein activity in b-cell chronic lymphocytic leukemia. Pharmacological reports : PR. 2006;58:720-728

12. Parker RB, Yates CR, Laizure SC, Weber KT. P-glycoprotein modulates aldosterone plasma disposition and tissue uptake. Journal of cardiovascular pharmacology. 2006;47:55-59

13. Uhr M, Holsboer F, Muller MB. Penetration of endogenous steroid hormones corticosterone, cortisol, aldosterone and progesterone into the brain is enhanced in mice deficient for both mdr1a and mdr1b p-glycoproteins. Journal of neuroendocrinology. 2002;14:753-759

14. Zolk O, Jacobi J, Pahl A, Fromm MF, Schmieder RE. Mdr1 genotype-dependent regulation of the aldosterone system in humans. Pharmacogenetics and genomics. 2007;17:137-144

15. Ueda K, Okamura N, Hirai M, Tanigawara Y, Saeki T, Kioka N, Komano T et al. Human p-glycoprotein transports cortisol, aldosterone, and dexamethasone, but not progesterone. The Journal of biological chemistry. 1992;267:24248-24252

16. Nakamura T, Okamura N, Yagi M, Omatsu H, Yamamori M, Kuwahara A, Nishiguchi K et al. Effects of abcb1 $3435 c>t$ genotype on serum levels of cortisol and aldosterone in women with normal menstrual cycles. Genetics and molecular research : GMR. 2009;8:397-403

17. Stern N, Lustig S, Petrasek D, Jensen G, Eggena P, Lee DB, Tuck ML. Cyclosporin a-induced hyperreninemic hypoaldosteronism. A model of adrenal resistance to angiotensin ii. Hypertension. 1987;9:III31-35

18. Lustig S, Stern N, Eggena P, Tuck ML, Lee DB. Effect of cyclosporin on blood pressure and reninaldosterone axis in rats. The American journal of physiology. 1987;253:H1596-1600

19. Bochud M, Bovet P, Burnier M, Eap CB. Cyp3a5 and abcb1 genes and hypertension. Pharmacogenomics. 2009;10:477-487

20. Eap CB, Bochud M, Elston RC, Bovet P, Maillard MP, Nussberger J, Schild L, et al. Cyp3a5 and abcb1 genes influence blood pressure and response to treatment, and their effect is modified by salt.

Hypertension. 2007;49:1007-1014 
21. Gouin-Thibault I, Delavenne X, Blanchard A, Siguret V, Salem JE, Narjoz C, Gaussem P et al. Interindividual variability in dabigatran and rivaroxaban exposure: Contribution of abcb1 genetic polymorphisms and interaction with clarithromycin. J Thromb Haemost. 2017;15:273-283

22. Schulte HM, Monig H, Benker G, Pagel H, Reinwein D, Ohnhaus EE. Pharmacokinetics of aldosterone in patients with addison's disease: Effect of rifampicin treatment on glucocorticoid and mineralocorticoid metabolism. Clin Endocrinol (Oxf). 1987;27:655-662

23. Bello-Reuss E, Ernest $\mathrm{S}$, Holland $\mathrm{OB}$, Hellmich MR. Role of multidrug resistance p-glycoprotein in the secretion of aldosterone by human adrenal nci-h295 cells. American journal of physiology. Cell physiology. 2000;278:C1256-1265

24. Lacchini R, Figueiredo VN, Demacq C, Coeli-Lacchini FB, Martins LC, Yugar-Toledo J, Coca A et al. Mdr-1 c3435t polymorphism may affect blood pressure in resistant hypertensive patients independently of its effects on aldosterone release. Journal of the renin-angiotensin-aldosterone system : JRAAS.

2014;15:170-176

25. Takeda R, Miyamori I, Ikeda M, Koshida H, Takeda Y, Yasuhara S, Morise T et al. Circadian rhythm of plasma aldosterone and time dependent alterations of aldosterone regulators. J Steroid Biochem. 1984;20:321-323

26. Tramonti G, Xie P, Wallner El, Danesh FR, Kanwar YS. Expression and functional characteristics of tubular transporters: P-glycoprotein, pept1, and pept2 in renal mass reduction and diabetes. Am J Physiol Renal Physiol. 2006;291:F972-980

27. Knops N, van den Heuvel LP, Masereeuw R, Bongaers I, de Loor H, Levtchenko E, Kuypers D. The functional implications of common genetic variation in cyp3a5 and abcb1 in human proximal tubule cells. Molecular pharmaceutics. 2015;12:758-768

\section{LEGENDS FOR FIGURES}

FIGURE 1. Effect of clarithromycin and P-gp genotype on hormone levels: (A) plasma renin concentration (PRC), (B) plasma aldosterone concentration (PAC), (C) Urinary aldosterone (UA)/creatinine ratio, and (D) urinary free cortisol excretion (UFC) / creatinine ratio by genotype before (white bars) and after 5 days of clarithromycin $500 \mathrm{mg}$ b.i.d. (grey bars). Bars show the medians and interquartile ranges (Q1-Q3) for homozygous wild-type ( $\mathrm{P}$-gp0 group), heterozygous mutated ( $\mathrm{P}$ gp1 group), and homozygous mutated (P-gp2 group) for haplotype 2677G>T/A-3435C>T subjects.

FIGURE 2. Potential influences of P-gp loss-of-function on aldosterone metabolism at baseline and after clarithromycin treatment: $\mathrm{P}$-gp is expressed in many tissues and is potentially involved in adrenal secretion of aldosterone and in biliary and renal aldosterone clearance. P-gp protects tissues from aldosterone impregnation. No effect of the 2677G $>$ T/A-3435C $>$ T loss-of-function polymorphisms was observed at baseline (panel A). Under clarithromycin, a potent CYP3A4 and P-gp inhibitor, we observed an increase in UAE and an increase in plasma aldosterone concentration, compatible with a decrease in extrarenal/biliary clearance of aldosterone (panel B). This effect was significant in P-gp1 and P-gp2 subgroups. 
Figure 1

A

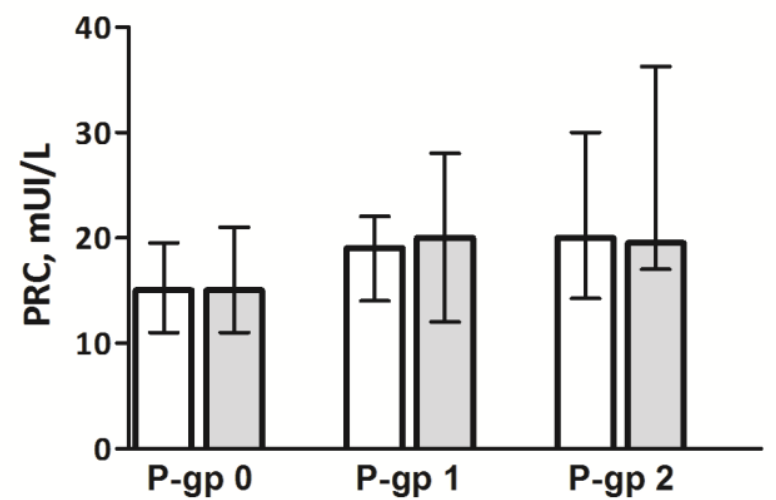

C

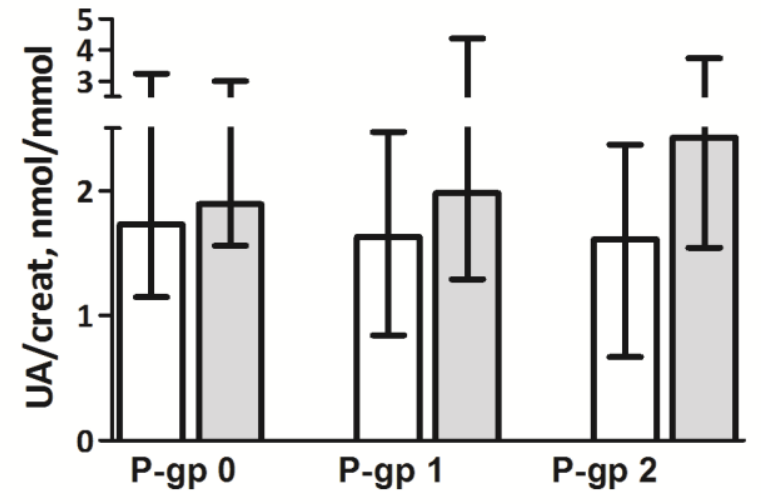

B

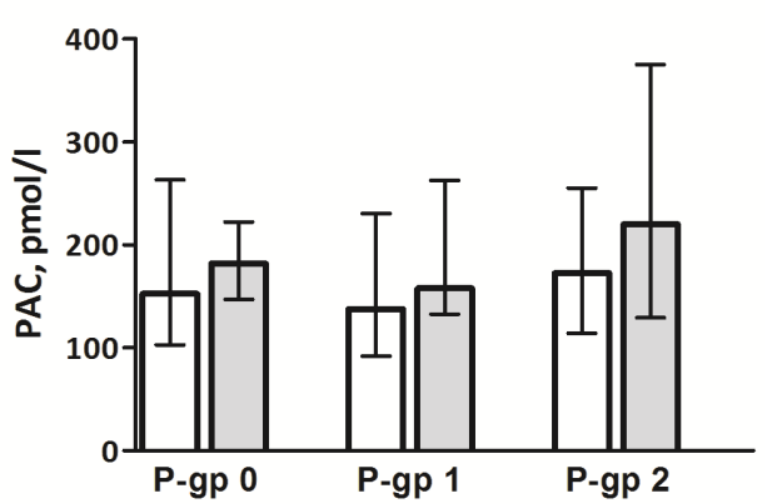

D

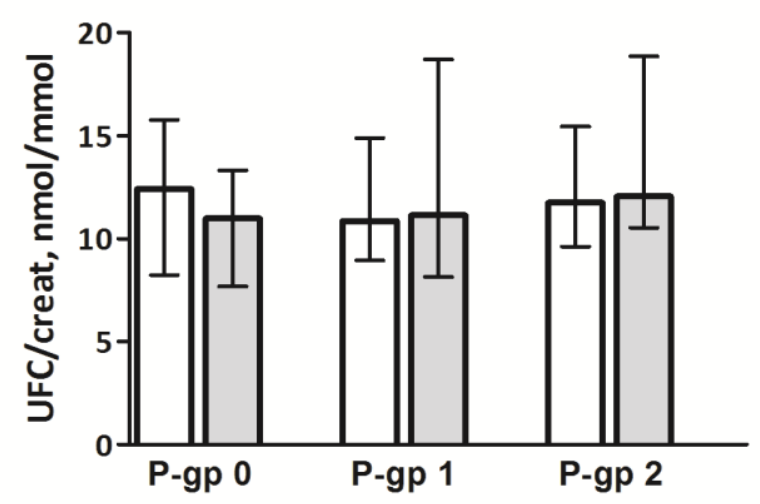


Figure 2:

(a)

(b)

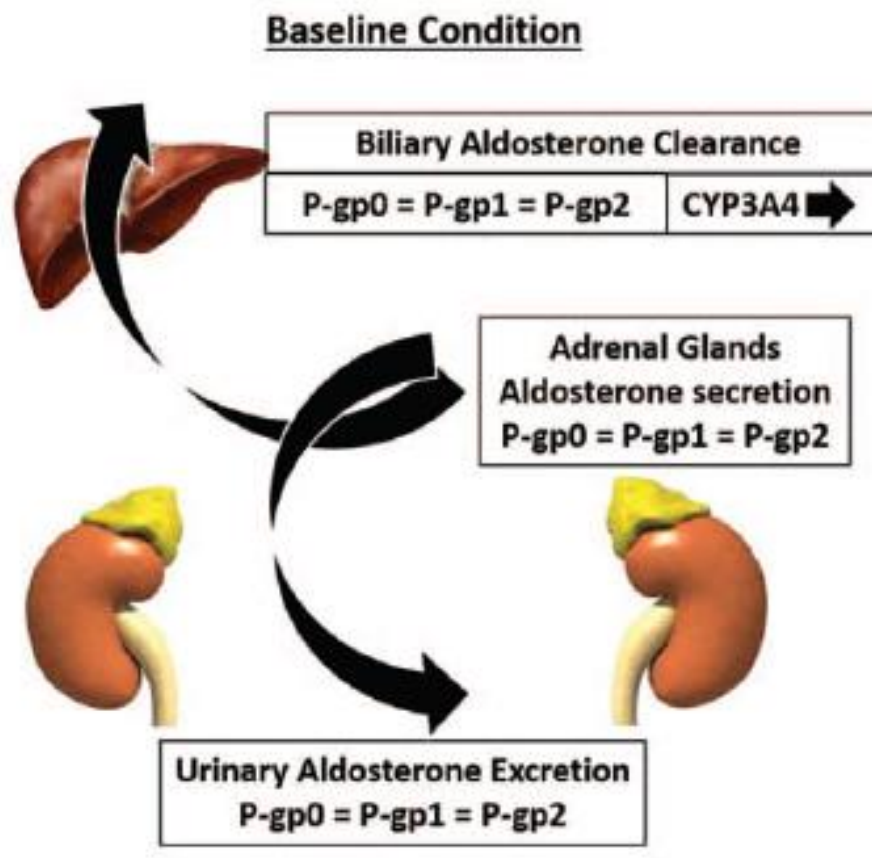

P-gp inhibition after 5 days of clarythromycin

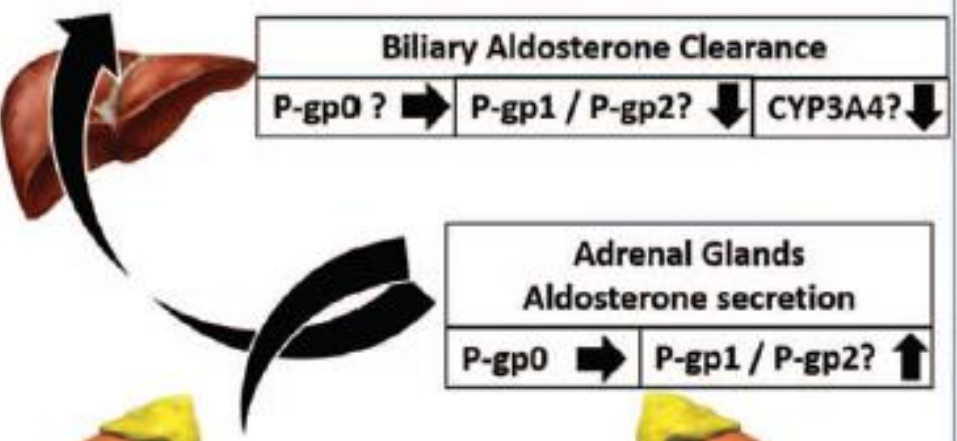

e

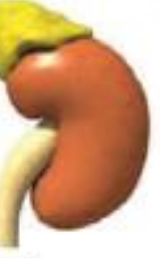

Urinary Aldosterone Excretion

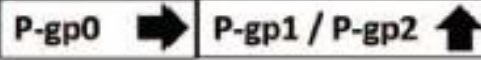

